\title{
Social and Clinical Profiling among Chronic Alcohol Dependent Men and Women Attending AA Groups in Trinidad
}

\author{
Rainah Seepersad ${ }^{1}$, Hari D Maharajh ${ }^{2}$ \\ ${ }^{1}$ Department of Clinical Medicine, University of the West Indies, Champs Fleurs, Mt. Hope, Trinidad, West Indies; ${ }^{2}$ Department of \\ Clinical Medicine, University of the West Indies, Champs Fleurs, Mt. Hope, Trinidad, West Indies. \\ Email: rainahs@hotmail.com,drharimaha@gmail.com
}

Received April 11 ${ }^{\text {th }}$ 2010; revised August 13 ${ }^{\text {th }}, 2010$; accepted September $13^{\text {th }}, 2010$.

\begin{abstract}
Background: Alcoholics Anonymous (AA) is well established in Trinidad and serves as an indispensable modality in the rehabilitation of alcoholics. This study investigates the gender differences in socio-demographic characteristics and clinical presentation of AA members in Trinidad. Method: Data were collected along the following variables: age, gender, ethnicity, religion, age of onset of alcohol use, psychiatric diagnoses and intentions for seeking treatment. An investigation of 107 members attending AA groups in Trinidad was conducted and analyzed utilizing a demographic questionnaire and the Michigan Alcohol Screening Test (MAST). The Statistical Package for the Social Sciences (SPSS, Version 16) was used to conduct all statistical analyses. Results: The age of the sample ranged from 22 to 78 with a mean age of 48.01 Males dominated the sample, accounting for $68 \%(n=73)$, while females were $32 \%(n=34)$. In terms of Ethnicity, East Indians accounted for 62\% $(n=65)$ of the sample, Africans 14\% $(n=15)$, Mixed 16\% $(n=17)$ and other $7 \%(n=7)$. Religious constitution was dominated by Hindus 36\% $(n=38)$, Roman Catholics $21 \%(n=22)$, other 14\% ( $n=15)$, Presbyterian 10\% ( $n=11)$, Pentecostal 9\% $(n=10)$, Muslim 5\% $(n=6)$ and Anglican 4\% $(n=5)$. Results utilizing the t-test showed that mean scores for males versus females differed significantly from each other $(\mathrm{t}$ $(1,105)=2.11, p=0.036)$ with males having a higher score on the MAST compared to females. Overall $14 \%$ of individuals indicated to having a co-morbid psychiatric disorder of which $10.5 \%$ were depression. Conclusion: Significant differences existed between genders in the clinical presentation of alcohol dependence. The composition and structure of AA groups in Trinidad is fashioned on a male gender bias. There is a need to address specific gender issues in the treatment of female alcoholics.
\end{abstract}

Keywords: Alcoholics Anonymous, Gender, Alcohol, Trinidad and Tobago, Ethnicity

\section{Introduction}

The higher preponderance of male alcoholics worldwide has resulted in alcohol dependence being primarily investigated as a disorder with a male gender bias. There is sufficient evidence however, that substance use affects men and women in different ways, in terms of its antecedents and its consequences [1]. When compared to men, there are few studies addressing the unique issues of alcohol dependence among women [2].

Within the Caribbean region, investigators have been reluctant to study alcohol dependence in females because the rates have been lower than that of males. Women tend to be closet drinkers and perceived stigmatization is increased with disclosure [3]. Little is known about alcohol dependence in women with some researchers claiming that the onset, course, diagnosis, prognosis and treatment are different to that of the male gender [4-10]. Due to the social role changes, it is becoming more evident that there are gender changes in the drinking patterns which are approaching the consumption rates of men [11]. In Trinidad with its economic affluence, there has been a social change in the pattern of drinking among women. They are no longer secret drinkers but drink openly in bars and public places.

Alcohol abuse is five times more frequent in men than in women with men being more likely to be binge drinkers and alcoholics than women. However, the incidence of 
alcohol dependence in women has been on the rise over the past 30 years and research has shown that they tend to become alcoholics later in life than men, but the condition has a faster progression in women [12]. For many years, women were perceived as not suffering from substance abuse problems to the same extent as men, and this perception, coupled with the intense social stigma associated with substance abuse, has created a situation in which women have been inadequately diagnosed, treated and studied. With American women closing the historic gender gap in drinking and drug usage [13], it is likely that the Caribbean has followed suit.

There are three to four times as many male heavy drinkers, problems drinkers, and alcoholics as there are female and the disproportions between men's and women's drinking have remained constant over time, [14-16]. The influence of gender role socialization has been attributed to the sex difference in alcohol use and alcohol problems accounting for higher rates of male drinkers. Gender roles reflect socially constructed beliefs about different ways in which men and women are expected to act in a given culture. Male and female gender roles are multidimensional [17-19] incorporating masculine and feminine-typed personality traits and behaviours, as well as a wide range of liberal and traditional attitudes about men's and women's roles in society [20] and several gender related stressors [21,22].

Worldwide the most notarized alcoholic treatment modality has been the Alcoholics Anonymous (AA) groups. AA has been established in Trinidad and Tobago for fifty three years and has been a near miracle in the rehabilitation of alcoholics for whom there was no hope. Despite its effectiveness in its goal of maintaining both sobriety and serenity, a number of criticisms have been leveled at its meeting. Some of these are that they substitute alcohol addiction with caffeine addiction, gambling and confessions based on pathological liars; that they do not appeal to younger alcoholics who having heard the life histories and experiences of older members conclude that they have not done enough to be in that group and women often feel alienated and insulted in mixed groups. Despite AA ideology not to be associated with any religious group, their dictum 'to improve our conscious contact with God as we understand him' and 'a spiritual wakening' in steps 3, 11 and 12, is often viewed by many as being too religious [23]. Notwithstanding its long and effective history of patients' recovery in Trinidad and Tobago, there are no comprehensive studies of this group other than its establishment by Michael Beaubrun in 1956 [24].

In Trinidad and Tobago, there is a narrowing gap in alcohol use with $56 \%$ of male respondents in a nationwide survey reported that they presently consume alcohol as compared to $44 \%$ of females. Interestingly, 70 percent of the male respondents indicated that they consumed alcohol everyday as compared to 30 percent of the female respondents [25], indicative of dependence being somewhat more prevalent among males. Sociodemographically the ethnic composition of alcoholics in Trinidad has been reported as being the highest among the Indian group [26] with alcohol dependence prevalence rates of $47 \%$ and $33 \%$ in persons of East Indian and African ancestry, respectively [27].

Screening for alcohol dependence among three populations, namely, alcoholics in treatment, clinical outpatients, and the general population, have indicated more males than females in each group report more alcohol-related problems overall [28]. Clinically this may be suggestive of differences in the phenomenology of alcohol dependence between genders.

\subsection{Aims and Objectives of Study}

This study seeks to investigate socio-demographic characteristics and clinical presentation of members attending AA groups in Trinidad. Data were collected along the following variables: age, gender, ethnicity, religion, age of onset of alcohol use, psychiatric diagnoses and intentions for seeking treatment. In addition, gender differences of symptoms of male and female alcoholics determined by the MAST-22 item were analysed.

\section{Materials and Methods}

\subsection{Description of Trinidad and Tobago}

Trinidad, and its sister isle of Tobago are the most southerly of all the Caribbean islands. It is located between the Caribbean Sea and North Atlantic Ocean, northeast of Venezuela. Its population is approximately 1.3 million, with $40 \%$ of its population being of East Indian descent $37.5 \%$ of African descent, 20.5\% Mixed, 1.2\% other and $0.8 \%$ unspecified [29]. Trinidad is divided into eight counties but for the purposes of this study the sample was chosen according to the Alcoholics' Anonymous (AA) division of groups within Trinidad (North, South and Central) as classified in the AA meeting list for Trinidad [23].

\subsection{Sample}

The data were collected from men and women attending Alcoholics Anonymous (AA) meetings throughout Trinidad. Groups were visited in the North, South, and Central regions of Trinidad. Interviews were conducted mostly in Schools and Health Centres and also from specialized treatment centres with AA Groups such as New Life Ministries Rehabilitation Centre, Piparo Empowerment Rehabilitation Centre, Families in Action, Serenity 
Place Women's Treatment Centre and the Caura Substance Abuse Prevention and Treatment Centre. A total of one hundred and sixteen (116) respondents participated in this study. Nine patients (9) were rejected due to insufficient information or withdrawal. The final analysis comprised of a sample of seventy three (73) men and thirty four (34) women who met the criteria for alcohol dependence according to the Michigan Alcohol Screening Test (MAST-22 item).

\subsection{Procedure}

Prior to data collection, approval was obtained from the Ethics Committee of the Faculty of Medical Sciences, University of the West Indies, at the Eric Williams Medical Sciences Complex and the Ethics Committee of the North West Regional Health Authority, Port of Spain. Alcoholics Anonymous (AA) meetings were randomly selected from a listing of the locations and times obtained at an AA meeting. Participants were informed that it was a strictly private and confidential study (an anonymous study) on alcoholism. Sealed envelopes were distributed containing the questionnaire which was asked to be returned by the next two meeting sessions, approximately six (6) days later. Participants were given the choice upfront to participate voluntarily, decline or withdraw from the research [30].

\subsection{Research Instruments}

\subsubsection{The Michigan Alcohol Screening Test (MAST)}

The MAST was developed by Selzer in 1971 and is useful for detecting dependent drinkers. The original tool has twenty five (25) questions but has been shortened to a twenty two (22) item and further brief ten (10) and thirteen (13) item versions. The questions relate to respondents' self appraisal of drinking habits and to social, vocational and familial problems frequently associated with excessive drinking. The sensitivity of the MAST is $86-98 \%$ and the specificity $81-95 \%$. The MAST (22-item) is useful as a case finder, to detect people who have serious alcohol problems, as it focuses on lifetime versus current drinking habits [31]. A total score of six (6) or more indicates hazardous drinking or alcohol dependence.

\subsubsection{Demographics}

Data were collected along the following variables: age, gender, ethnicity, and religion. Gender was defined as being either male or female. Age, ethnicity and religion were self reported. Age was an open category. Ethnicity was reported using one of the given response categories of the four main ethnic groups: East Indian, African, Mixed, and other. Religion was reported using one of the response categories given based on the major religions in
Trinidad and Tobago: Roman Catholic, Presbyterian, Anglican, Pentecostal, Seventh Days Adventist, Methodist, Hindu, Muslim, and Other [29].

\subsubsection{Questionnaire (structured from literature)}

Onset of use of alcohol was reported using the categories "younger than 12", “12-15,” "16-19,” "20-23,” “24-27," "28-31," and "32 or older." Respondents intentions or reasons for seeking treatment ware left open ended and further coded by the author based on responses into the categories of: "self/life became unmanageable/point of no return," "family," "work related reasons," "health reasons," "intervention," "spiritual reasons," and "Don't know." Even though multiple responses were allowed, participants gave a main reason that allowed for easy coding. Respondents' history of a diagnosis with a psychiatric disorder was assessed by self report for any of the following psychiatric disorders: Depressive disorder, Bipolar disorder, Post Traumatic stress disorder, Generalized Anxiety disorder, Antisocial Personality disorder and other (other was left open ended). This was based on previous diagnosis by a physician and was not reassessed at the time of data collection. The above variables were designed in such a way to resemble a clinical interview which would document a basic history of the participants' life.

\subsection{Statistical Analyses}

The Statistical Package for the Social Sciences (SPSS, Version 16) was used to conduct all statistical analyses. Differences were considered significant at $p<0.05$ level. Frequencies were utilized to describe the sample characteristics. The gender difference among the variables examined was measured using Pearson Chi Square test for independence. A test was used to determine if the mean scores on the MAST were significantly different between genders.

\section{Results}

A total of one hundred and sixteen (116) respondents were sampled across Trinidad for this study. All subjects that were approached participated. Due to the fact that some of the research instruments were incomplete or the respondent did not meet the criteria for alcohol dependence (6 or more on the MAST), nine respondents (9) were excluded. Thus, one hundred and seven (107) members were used for the analysis.

\subsection{Sample Characteristics}

The age of the sample ranged from 22 to 78 with a mean age of 48.01 and a standard deviation of 11.61. (Figure 1) It was found that males dominated the sample, accounting for $68 \%(n=73)$, while females were $32 \%$ 


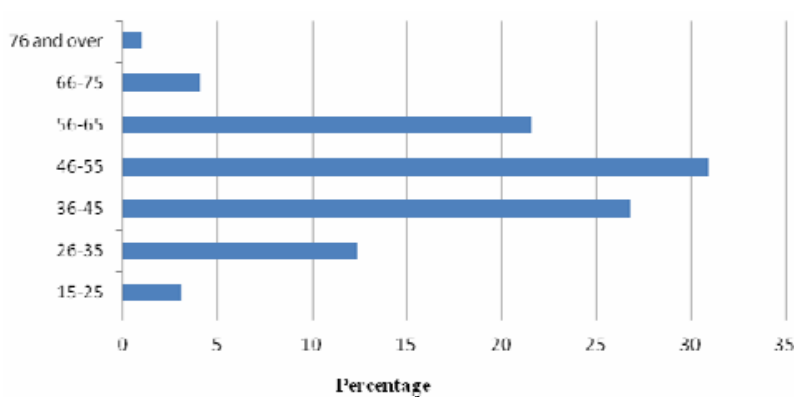

Figure 1. Percentage distribution of age range of alcohol dependents.

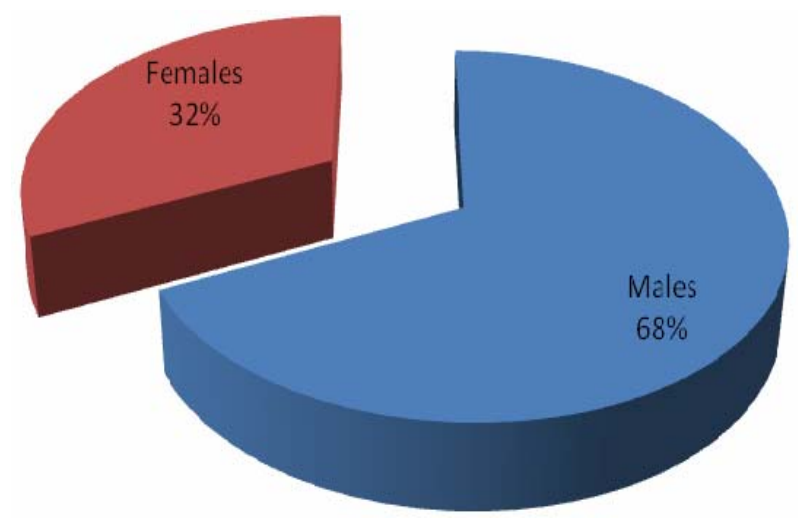

Figure 2. Percentage distribution of male to female alcohol dependents.

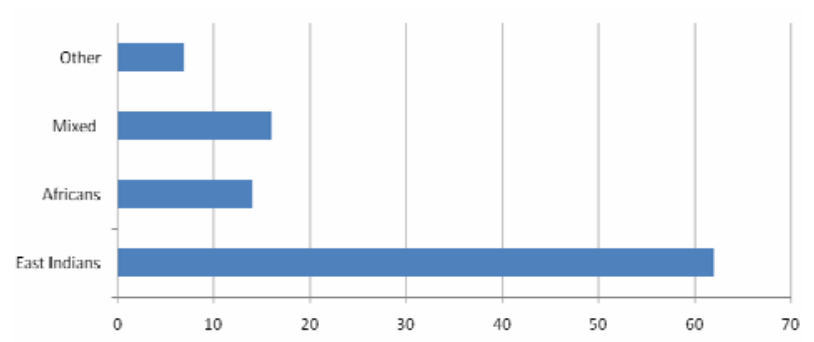

Figure 3. Percentage distribution of ethnic composition of alcohol dependents.

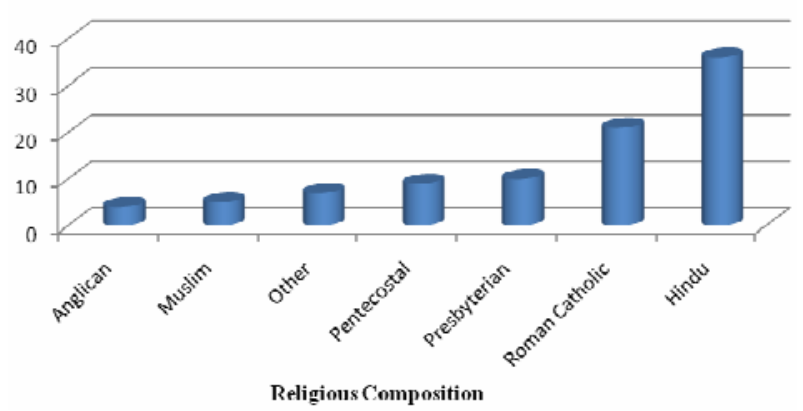

Figure 4. Percentage distribution of religious composition of alcohol dependents.

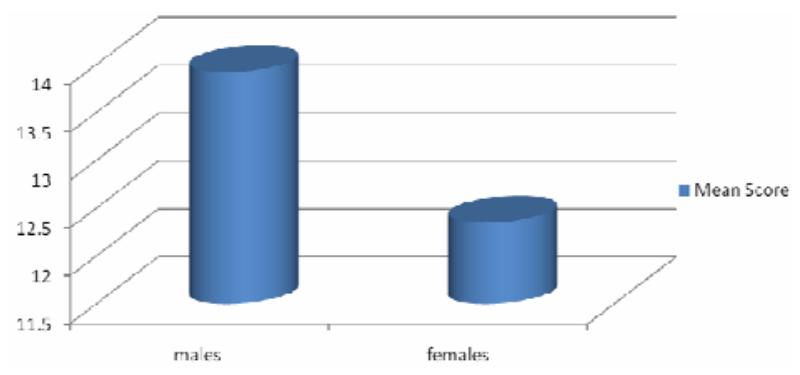

Figure 5. Differences in mean scores according to gender on the Michigan alcohol screening test.

( $n=34)$ as shown in Figure 2. In terms of Ethnicity, East Indians accounted for $62 \%(n=65)$ of the sample, Africans $14 \%(n=15)$, Mixed 16\% $(n=17)$ and other $7 \%(n$ = 7), (see Figure 3). Religious constitution was dominated by Hindus 36\% ( $\mathrm{n}=38$ ), Roman Catholics 21\% (n $=22)$, other $14 \%(n=15)$, Presbyterian $10 \%(n=11)$, Pentecostal 9\% $(n=10)$, Muslim 5\% $(n=6)$ and Anglican $4 \%(n=5)$. (See Figure 4$)$.

\subsection{Gender and Behaviour in Alcohol Dependence}

In this population scores on the MAST-22 item ranged from 6 to 21. Females had a mean score of 12.35, standard deviation 3.49 and males a mean score of 13.92, standard deviation 3.61. Results of the test showed that mean scores for males versus females differed significantly from each other $\left(t_{(1,105)}=2.11, \mathrm{p}=0.036\right)$ with males having a higher score on the MAST compared to females as illustrated in Figure 5.

Significant gender differences existed among six (6) questions on the MAST-22 item questionnaire (items 1,3 , 7, 9, 11 and 22) with respect to the phenomenology of alcohol dependence in men and women. A significantly higher percentage of women $59 \%(n=20)$ than $36 \%$ of men $(n=26)\left[X^{2}=5.097\right.$, d.f. $\left.=1, p<0.05\right]$ felt that they were a 'normal' drinker ('normal' defined as drinking as much or less than more other people). Ninety nine percent $(99 \%)$ of males $(n=72)$ in comparison to $88 \%$ females $(\mathrm{n}=30)\left[X^{2}=5.627\right.$, d.f. $\left.=1, \mathrm{p}<0.05\right]$ indicated that a near relative or close friend worried or complained about their drinking.

Significantly more men $75 \%(n=55)$ than women $41 \%(\mathrm{n}=14)\left[X^{2}=11.823\right.$, d.f. $\left.=1, \mathrm{p}<0.05\right]$ indicated that they got into physical fights when drinking. The majority of males $84 \%(n=61)$ reported that a family member or close friend has gone to someone for help about their drinking in comparison to $56 \%$ of women (n =19) $\left[X^{2}=9.420\right.$, d.f. $\left.=1, \mathrm{p}<0.05\right]$.

Seventy seven percent $(77 \%, n=56)$ of males in comparison to $53 \%(n=18)$ of women reported that they have gotten in trouble at work because of drinking, 
Table 1. Significant differences in behaviour of alcohol dependence in males and females.

\begin{tabular}{|c|c|c|c|c|c|c|}
\hline \multirow{3}{*}{ Items on the MAST ${ }^{\mathrm{a}}$} & \multicolumn{4}{|c|}{ Gender } & \multirow{3}{*}{$X^{2}$} & \multirow{3}{*}{ P-value } \\
\hline & \multicolumn{2}{|c|}{ Males } & \multicolumn{2}{|c|}{ Females } & & \\
\hline & (n) & Yes (\%) & (n) & Yes (\%) & & \\
\hline $\begin{array}{l}\text { 1. Did you feel you were a normal drinker? } \\
\text { (normal is defined as drinking as much or as less than most } \\
\text { people) }\end{array}$ & $(26)$ & 36 & $(20)$ & 59 & 5.097 & .024 \\
\hline $\begin{array}{l}\text { 3. Did any near relative or close friend ever worry or com- } \\
\text { plain about your drinking }\end{array}$ & $(72)$ & 99 & $(30)$ & 88 & 5.627 & .018 \\
\hline 7. Have you ever gotten into physical fights when drinking? & $(55)$ & 75 & $(14)$ & 41 & 11.823 & .001 \\
\hline $\begin{array}{l}\text { 9. Has any family member or close friend gone to anyone for } \\
\text { help about your drinking }\end{array}$ & $(61)$ & 84 & $(19)$ & 56 & 9.420 & .002 \\
\hline $\begin{array}{l}\text { 11. Have you ever gotten into trouble at work because of } \\
\text { drinking }\end{array}$ & $(56)$ & 77 & $(18)$ & 53 & 6.145 & .013 \\
\hline $\begin{array}{l}\text { 22. Have you ever been arrested, or detained by an official } \\
\text { for a few hours, because of other behavior while drinking? }\end{array}$ & $(25)$ & 34 & (2) & 6 & 9.892 & .002 \\
\hline
\end{tabular}

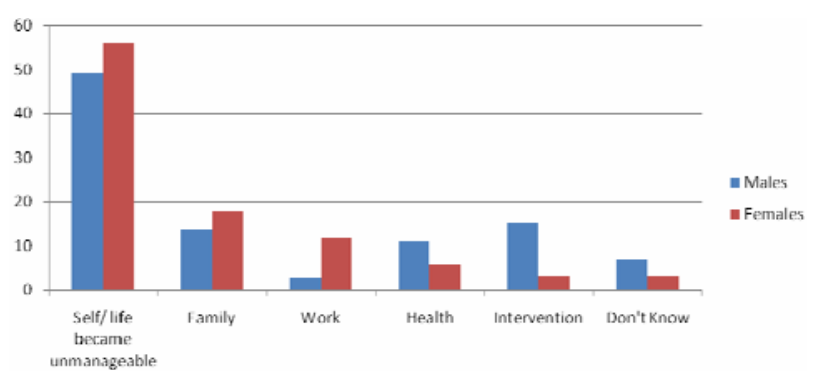

Figure 6. Percentage distribution of reasons for seeking treatment by gender.

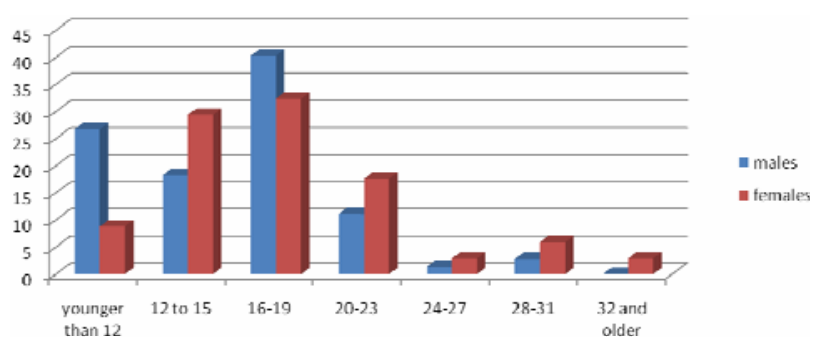

Figure 7. Percentage distribution of age of onset of alcohol use by gender.

Indicative of a significant difference $\left[X^{2}=6.145\right.$, d.f. $=1$, $\mathrm{p}<0.05]$. A significantly higher percentage of males $34 \%(n=25)$ than females 6\% $(n=2)$ indicated to have been arrested or detained by an official for a few hours, because of other behaviour while drinking (see Table 1).

\subsection{Gender and Treatment}

Among the respondents four major reasons were stated as to why treatment was sought. Fifty one percent (51\%) of individuals stated that their life had become unmanageable; most responses indicated a point of no return as they reported all aspects of their life were out of control. These individuals decided that treatment was the only way to save their life. Other respondents indicated that they sought treatment for main reasons such as family (15\%), intervention (12\%) and $11 \%$ indicated they sought treatment because of health reasons.

There were no significant gender differences with respect to the reasons for seeking treatment $\left[X^{2}=6.078\right.$, d.f. $=7, \mathrm{p}<0.05]$. The majority of both males $49 \%(\mathrm{n}=36)$ and females 56\% ( $=19)$ indicated that they sought treatment because they felt their life had become unmanageable and felt they reached a point of no return, (see Figure 6).

\subsection{Gender and Onset of Alcohol Use}

With respect to gender differences and the onset of alcohol consumption, $27 \%$ of males $(n=19)$ indicated that they began alcohol consumption before the age of 12 in comparison to $9 \%(n=3)$ of females who indicated the same presenting a significant difference in age of onset of alcohol consumption, $\left[X^{2}=4.47\right.$, d.f. $\left.=1, \mathrm{p}<0.05\right]$. Overall $37.7 \%$ of the sample indicated to having started consuming alcohol at the 16-19 age groups as illustrated in Figure 7.

\subsection{Psychiatric Diagnoses}

Overall $14 \%$ of individuals indicated to having a co-morbid psychiatric disorder, and there was no significant difference between genders with respect to the presence of a co-morbid psychiatric disorder $\left[X^{2}=5.44\right.$, d.f. $=1, \mathrm{p}<0.05]$, (see Figure 8).

\section{Discussion}

Our findings in Trinidad indicate that alcohol dependence at Alcoholics Anonymous meetings is dominated by males who account for $68.2 \%$ of the members seeking help. Government surveys in most countries usually report about three times as many male to female alcoholics 


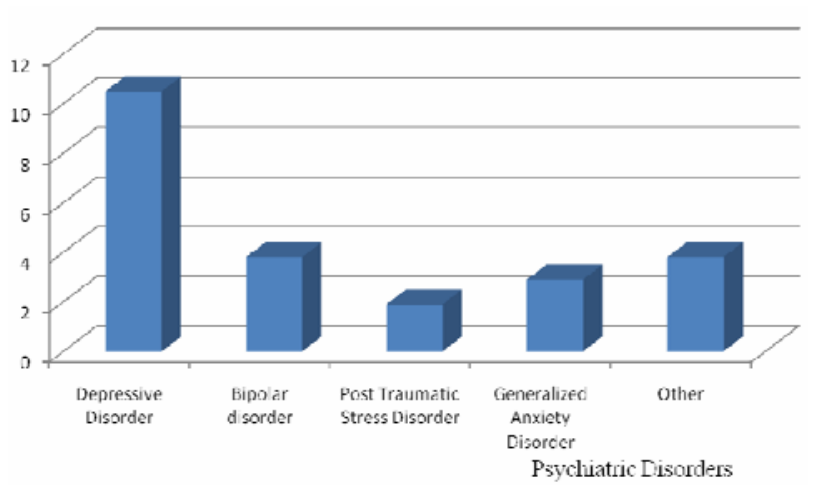

Figure 8. Percentage distribution of psychiatric disorders present in the alcohol dependent population.

[32], with the male gender being a strong predictor for alcohol dependence [12]. The present study narrows the gap, but men still maintaining more than twice the presence, compared to female alcohol dependent women. A major factor that accounted for the small number of women in the population is the underutilization of treatment centers by women [32], from which the present sample is sourced. A possible explanation for this is that women experience more difficulties when entering alcoholism treatment settings. Barriers for women seem to be the social stigma and the fear to lose the right to care for their children, once an alcohol problem is identified [32]. Women in Trinidad have reported that they do not attend meetings out of fear of being sexually harassed by men, a genuine fear that has been past experiences [33].

The utilization of the MAST in this study enabled the researchers to confirm a diagnosis of Alcohol dependence among AA members and also served to differentiate behavioral characteristics of differences in the male and female alcohol dependent persons. Males in the sample had higher mean MAST scores compared to females (13.92 vs. $12.35, \mathrm{p}<0.05)$ as suggested by previous studies have also indicated significant differences existing between male and female mean MAST scores. Males scoring higher on the MAST than females have suggested that males have a greater dependence for alcohol than females. These results are supported by several other studies that found alcohol frequency to be higher among males than females [34]. Generalization of these results is difficult as many studies are usually testing the MAST on specific populations such as solely men or college populations. This is due to the fact that the MAST was originally designed for a male population [35].

The majority of the present sample was ethnically saturated with individuals of East Indian descent (62.5\%) in comparison to those of African descent (14.4\%). The prevalence of alcohol dependence in Trinidad and
Tobago is higher than in the United States and also among individuals of East Indian ancestry when compared with those of African ancestry [36]. Research in Trinidad has reported alcoholism as being the highest among the Indian groups [37] with a recent assessment survey reporting alcohol dependence prevalence rates of $47 \%$ and $33 \%$ in persons of East Indian and African ancestry, respectively [36]. Notably though, the population of Trinidad being multi-ethnic and mainly composed of people of East Indian (40\%) and African ancestry (37.5\%) may account for ethnic differences in prevalence rates, [29]. Similar findings with respect to the ethnic population consuming alcohol can also be identified among high school students, in Trinidad and Tobago, [37]. However, the majority of the population sampled was sourced from South and Central Trinidad where larger AA groups are located, but also notably denser East Indian populated areas. Among the East Indian population the Hindu religion is more dominant accounting for the large percentage of individuals (36\%) from this religious background. The authors have noted that there is an ethnic reversal of alcohol and drug use in Trinidad and Tobago with Indo-Trinidadians having a tendency to favor the use of licit drugs such as alcohol and tobacco while Afro-Trinidadians favor illicit drugs such as marijuana and cocaine. This is associated with the high level of crime among the latter group.

It is also noteworthy that due to the family structures in the Caribbean, there is an immense pressure among Indo-Trinidadian families, especially extended families, to seek help for their loved ones because of strong kinship ties [37]. This has been linked to ethno-cultural traditional values and issues from the post-indenture ship reconstitution of the Indo-Trinidadian society. East Indians resisted Christian indoctrination and organized themselves into small communities under the "panchayat system” led by Brahmin pundits [38]. This enabled easy resolution of social and psychological problems of the community. Hence, one can speculate that Indo-Trinidadians will be naturally attracted to such "satsang" (group discussions), like AA meetings.

There were also significant differences in the symtomatology of the profile of scores measured on the MAST. The MAST's results have been noted to be sensitive to demographic variables in the past. Previous researchers have demonstrated that men and women experience alcohol dependence and the concomitant symptoms and consequences differently. The MAST's original standardization sample was composed primarily of males convicted of driving under the influence [35]. As such, the MAST may be measuring different traits in men than it does in women. This is supported by the present study in which more males indicated to having been involved 
in negative legal behavior, specifically "being arrested or detained by an official for a few hours, because of other behavior while drinking" compared to women (34\% vs. $6 \%$ respectively). More males (75\%) also indicated "to have been in physical fights when drinking" compared to women (41\%). Findings were found in a United States population between men and women $(40.2 \%$ vs. $32.7 \%$ respectively), [39] indicating more males than females express this form of aggressive behavior. Interestingly though, it was found that more men had family members who complained or worried about them, or even went for help about their drinking. This interesting finding has been noted in previous research that women are less likely to receive support from family members or friends to enter treatment [40]. Within the Indo-Trinidadian population, there is less tolerance to female deviancy than that of the male gender. The male offspring is traditionally the favored child and carries more prestige than the female. This pattern is now changing as female offsprings are now actively involved in the care of both their maternal and marital families.

In addition, diversity of educational history and age has been known to affect MAST results. For instance, education has been linked to awareness and ability to identify the signs and symptoms of alcohol dependence [35]. The present population having been sourced at AA meetings where education about alcoholism inclusive of signs and symptoms are regularly reviewed may have influenced the sample to more readily disclose information about their alcohol dependence because of their awareness. The authors have recognized the influences of AA on the members. Their language, thought and behavior is modulated by the philosophy of AA; their responses are posited in language of AA, for example on questioning why they sought help for their problems, the majority of men and women stated that their lives had become unmanageable downplaying initial forced family treatment.

Alcohol-dependence symptom development may be a function of age $[41,42]$ but according to the present study this was not supported indicating that in the Trinidad population, age and increased scores on the MAST were not significantly correlated in a positive direction ( $\mathrm{r}=$ $-1.18, \mathrm{p}<0.05)$. Thus, the MAST's usefulness with young and undereducated clients may not apply to alcohol dependents in Trinidad. This finding may be due to the fact that the population studied were not presently chronic drinkers, hence older individuals was the majority of the sample as respondents were sober for many years. It would have been useful to break down ethnicity and age by gender, but this was restricted by small sample size.

In terms of the age of onset reported, the findings suggested that higher rates of males start using alcohol at an earlier age than women (26.8\% vs. $8.8 \%$ ) respectively. Historically, men have reported an earlier age of onset of alcohol use initiation than women $[43,44]$. In the present research the findings indicated that more men began drinking at an earlier age at the 'younger than 12 age group.

With respect to similar age of onset most men and women started using alcohol around 16-19 age group in this research as it pertains to Trinidad. Likewise, other researchers have found remarkable similarity, with no significant differences in age of onset of male and female alcohol use leading to alcohol dependence. Interestingly, among persons who begin drinking before age 14 years, 45\% develop diagnosable dependence compared with $10 \%$ of persons who wait until they are 21 years or older [45]. In this research more males began consumption of alcohol before females which may also account to the saturation of males in the study.

Individuals with Alcohol use disorders such as alcohol dependence frequently meet criteria for other psychiatric disorders as well. Recent data from the National Epidemiologic Survey on Alcohol and Related Conditions (NESARC) reveal that among individuals with alcohol dependence, $15.15 \%$ met the criteria for a depressive disorder [44], of which similar findings were found in the present research (10.5\%). It was also noted that in AA the camaraderie of the programme invokes overzealous behavior among its members that may influence the usual depressive symptoms associated with alcohol dependence. A local psychiatrist who has worked closely with AA has observed that AA seems to be a self perpetuating group with an overzealous and enthusiastic approach. One of his patient's introductions into AA resulted in a Bipolar disorder. He has noted a 'high' amongst many AA members triggered by the new culture of the group process, personal disclosures, and storytelling combined with the historical development of Alcoholics Anonymous. Subsequently members are apt to be less negative in their outlook of life because of the new control they now have over their life [46].

With respect to treatment formulation women seeking pathways to recovery in institutionalized settings may be more likely to be screened for psychiatric disorders, but the reality of their condition becoming worse before they seek treatment may be more likely, since women tend to hide their drinking behavior. This prevents friends, family and physicians from detecting alcohol dependence in many females [47]. This may account for the absence of diagnoses of co morbid disorders in this present study.

Recent findings though, may reflect a change in women's access to substance abuse care, which may be caused by reductions in stigma, increased awareness of 
alcohol problems and greater availability of womenfocused treatment programs [40]. In Trinidad today, there is one AA group and one treatment centre that accommodates women only and has provided an avenue for women to seek help without stigmatization. This point to the vital role of alcohol treatment services in non addiction settings in spite of the provision of mental health care by general medical providers or primary care physicians [40]. AA has been traditionally viewed as a male oriented form of group therapy due to the established culture. The needs of women are not often expressed or addressed. Despite the fact, that there are less women attracted to AA in one select sample and is skewing towards males, women in Trinidad still seek treatment for alcohol dependence at AA groups and this has to be addressed in future research.

There is little doubt that AA in Trinidad has helped thousands of alcoholics and their families and would continue to do so in the future. Socio-demographic factors obtained from this study, profile the AA member in Trinidad as being a middle age (48 years), male Indo-Trinidadian of the Hindu religion who began abusing alcohol in their adolescent period. They invariably have good family support that results in forced treatment and the commonest psychiatric disorder associated with their alcohol dependence is a Depressive disorder. This in itself facilitates the group process of AA that provides a cognitive-behavioral approach to the treatment of both addiction and depression as members work through the structured twelve steps and traditions. Traditional values and culture seem to have an important part to play in the treatment process but is often underplayed due to the philosophy of AA.

The differences observed here in the female alcoholic raises a number of pertinent issues. Over the years the male and female alcoholics were painted with the same brush. It is evident that the female alcoholic has special needs and the onset, course, presentation and treatment modalities of women may be different to those of men. It was also noted that the entertainment quotient and sexual innuendos delivered at discourses at AA meetings often ridicule women. These findings suggest that women have special and separate needs in treatment and future investments should be tailored to female only Treatment Centers.

It is the view of the authors that $\mathrm{AA}$ is the most effective treatment modality for alcohol dependents. However we have pointed out that there are limitations to its use with respect to the level of chronicity, age, ethnicity, gender and socio-cultural practices.

The findings of this research cannot be generalized to individuals in the general population who have abused alcohol but have not met the criteria for Alcohol
Dependence. Nor can it be applied to individuals who have not sought treatment for their alcohol dependence. It is important to view that the data collecting describes differences between male and female AA members and not male and female alcohol dependent individuals. This view is arbitrary since the paper specifies that all members at AA groups were previously described as alcohol dependents.

\section{REFERENCES}

[1] C. S. Widom and S. Hiller-Sturmhofel, "Alcohol Abuse as Risk Factor for and Consequence of Child Abuse," Alcohol Research and Health, Vol. 25, No. 1, 2001, pp. 52-57.

[2] D. Wilke, "Women and Alcoholism: How a Male-as-Norm Bias Affects Research, Assessment, and Treatment," Health and Social Work, Vol. 19, No. 1, 1994, pp. 29-35. August 2009. http://www.questia.com/googleScholar.qst; jsesionid=KQDFhxptjj8CfNnP31jjqhkyKTV6JltpLSR3Jfy pQ37S22tNCJJQ!-229138872!-1934322800?docId=50001 87462

[3] J. Fortney, S. Mukherjee, G. Curran, S. Fortney, X. Han and B. M. Booth, "Factors Associated With Perceived Stigma for Alcohol Use and Treatment Among At-Risk Drinkers.” Journal of Behavioral Health Services \& Research, Vol. 31, No. 4, 2004, pp. 418-29. August, 2009. http://www.pringelink.m/content/y8t4672877u57657/

[4] L. J. Beckmann and H. Amaro, "Personal And Social Difficulties Faced by Women and Men Entering Alcoholism Treatment," Journal of Studies on Alcohol and drugs, Vol. 47, No. 2, 1986, pp. 135-145.

[5] D. Dawson, "Gender Differences in the Risk of Alcohol Dependence: United States, 1992,” Addiction Journal, Vol. 91, No. 12, 1996, pp. 1831-1842.

[6] A. Franke, K. Elesser, F. Sitzler, G. Algermissen and S. Kotter, "Gesundheit und Abhangigkeit Bei Frauen: Eine Salutogenetische Verlaufsstudie,” Runge, Cloppenburg, 1998.

[7] A. Franke, K. Mohn, F. Sitzler, M. Welbrink and M. Witte, "Alkohol-und Medikamentenabhangigkeit von Frauen,” Risiken und Widerstansfaktoren, Juventa, Weinheim, 2001.

[8] D. W. Hommer, R. Momenan, E. Kaiser and R. Rawlings, "Evidence for a Gender Related Effect of Alcoholism on Brain Volumes,” The American Journal Psychiatry, Vol. 158, No. 2, 2001, pp. 198-204.

[9] C. L. Randall, J. S. Roberts and F. K. Del Boca, "Telescoping of Landmark Events Associated with Drinking: a Gender Comparison,” Journal of Studies on Alcohol, Vol. 60, No. 2, 1999, PP. 252-260.

[10] S. F. Tapert, G. G. Brown, S. S. Kinderman, E. H. Cheung, R. F. Lawrence and S. A. Brown, "fMRI Measurement of Brain Dysfunction in Alcohol Dependent Young Women," Alcoholism: Clinical Experimental Research, Vol. 25, No. 2, 2001, pp. 236-245. 
[11] C. A. Hernandez-Avila, B. J. Rounsaville and Kranzler HR, “Opioid-, Cannabis- and Alcohol-Dependent Women Show More Rapid Progression to Substance Abuse Treatment,” Drug and Alcohol Dependence, Vol. 74, No. 3, 2004, pp. 265-272.

[12] A. Scholten, "Risk Factors for Alcohol Abuse and Alcoholism,” 2007. August 2009. http://www.aurorahealthcare. org/yourhealth/healthgate/getcontent.asp?URLhealthgate $=\% 2219041 . h t m l \% 22$.

[13] M. D. Stein and M. G. Cyr, "Women and Substance Abuse,” Medical clinics of North America, Vol. 81, 1997, pp. 978-998.

[14] R. Lemle and M. E. Mishkind. "Alcohol and Masculinity,” Journal of Substance Abuse Treatment, Vol. 6, 1989, pp. 213-222.

[15] J. Stillion, "Premature Death among Males: Extending the Bottom Line of Men's Health,” In: D. Sabo \& D. F. Gordon, Ed., Men's Health and illness: Gender, power, and the body, Thousand Oaks, CA: Sage, 1995, pp. 46-67.

[16] I. Waldron, "Contributions of Changing Gender Differences in Behavior and Social Roles to Changing Gender Differences in Mortality,” In: D. Sabo \& D. F. Gordon, Ed., Men's Health and illness: Gender, power, and the body, Thousand Oaks, CA: Sage, 1995, pp. 22-45.

[17] D. R. McCreary, "Multidimensionality and the Measurement of Gender Roles Attributes: A comment on Archer," British Journal of Social Psychology, Vol. 29, 1990, pp. 265-272.

[18] J. T. Spence, "Masculinity, Femininity and Gender Related Traits: A Conceptual Analysis and Critique of Current Research,” In: B. A. Maher, Ed., Progress in experimental personality research, New York: Academic, Vol. 13, 1984, pp. 1-97.

[19] J. T. Spence, "Gender Related Traits and Gender Ideology: Evidence for a Multi-Factorial Theory," Journal of Personality and Social Psychology, Vol. 64, 1993, pp. 624-635.

[20] E. H. Thompson, J. H. Pleck and D. L. Ferrera, "Men and Masculinities: Scales for Masculinity Ideology, and Masculinity Related Constructs,” Sex Roles, Vol. 27, 1992, pp. 573-607.

[21] R. M. Eisler, “The Relationships between Masculine Gender Role Stress and Men's Health Risk: The Validation of a Construct," In: R. F. Levant \& W. S. Pollack, Ed., The new Psychology of men, New York, Basic Books, 1995, pp. 207-225.

[22] J. M. O’Neil, G. E. Good and S. Holmes, "Fifteen Years of Theory and Research on Men's Gender Role Conflict: New Paradigms for Empirical Research,” In: R. Levant \& W. Pollack, Ed., A new Psychology of men, New York: Basic Books 1995, pp 207-225.

[23] Alcoholics Anonymous Grapevine, “A Brief Guide to Alcoholics Anonymous,” New York, 1972.

[24] M. Beaubrun, "Treatment of Alcoholism in Trinidad and Tobago 1956-65,” British Journal of Photography, Vol.
113, 1967, pp. 643-658. August 2009.http://bjp.rcp ych. org/cgi/cotent/abstract/113/499/643

[25] R. Mc Clean, "The National Drug Abuse Demand Reduction Survey," The National Alcohol and Drug Abuse Prevention Programme, 1999, pp. 9-10.

[26] R. Parasram, "Ethnic differences in Reported Rates of Alcoholics in Trinidad and Tobago," Paper presented at the International Congress on Alcoholism and Drug Dependence, August 1995, pp. 4-10.

[27] National Alcohol and Drug Abuse Prevention Center, 2000.

[28] A. K. Chan, E. A. Pristach and J. W. Welte, "Detection of Alcoholism in Three Populations by the Brief-MAST," Alcoholism: Clinical and Experimental Research, Vol. 18, No. 3, 1994, pp. 695-701.

[29] “The World FactBook, Trinidad and Tobago,” August 2009.http://www.ece.gov.nt.ca/Maps/World\%20and\%20 Canada\%20Maps\%20Publish/factbook/print/td.html

[30] American Psychological Association, "The Publication Manual of the American Psychological Association," 5th Edition, Washington, DC, July 2001.

[31] Alcohol Concern Primary Care Alcohol Information Service, Factsheet, "Screening Tools for Healthcare Settings, (Brochure),” Waterbridge House, London.

[32] H. Walter, K. Gutierrez, K. Ramsklogler, I. Hertling, A. Dvorak and O. M. Leasch "Gender-Specific Differences in Alcoholism: Implications for Treatment," Archives of Women's Mental Health, Vol. 6, 2003, pp. 253-58.

[33] Personal Communication. AA member. June 27, 2009.

[34] M. Moulton "Generic Alcoholism: “Are College Athletes at Risk?” The Sport Journal, Vol. 3, No. 2, 2000, pp. 45-50.

[35] J. M. Laux, I. Newman and R. Brown, "The Michigan Alcoholism Screening Test (MAST): A Statistical Validation Analysis," Measurement and Evaluation in Counselling and Development, Vol. 36, No. 4, 2004, p. 209.

[36] S. Moore "Association of ALDH1 Promoter Polymorphisms with Alcohol-Related Phenotypes in Trinidad And Tobago,” Journal of Studies on Alcohol, Vol. 68, No. 2, 2007, pp. 192-196. August 2009. http://fin articles.com/p/articles/mi_hb6378/is_2_68/ai_n29385205

[37] H. D. Maharajh and A. Ali, "Social Predictors of Suicidal Behavior in Adolescents in Trinidad And Tobago," Social Psychiatry and Epidemiology, Vol. 40, 2005, pp. 186-191.

[38] H. D. Maharajh and R. Parasram, "The Practice of Psychiatry in Trinidad and Tobago,” International Review of Psychiatry, Vol. 11, 1999, pp. 173-183.

[39] A. Burnam, "Prevalence of Alcohol Abuse and Dependence among Mexican Americans and Non-Hispanic Whites in the Community,” In: D. Spiegler, Ed., Alcohol Use among U.S Ethnic Minorities, Proceedings of a Conference on the Epidemiology of Alcohol Use and Abuse among Ethnic Minority Groups. DIANE, 1993.

[40] L. Wu and C. L. Ringwalt, “Alcohol Dependence and Use of Treatment Services among Women in the Commu- 
nity,” The American Journal of Psychiatry, Vol. 161, No. 10, 2004, pp. 1790-1797.

[41] E. S. Hirata, O. P. Almeida, R. R. Funari and E. L. Klein, "Validity of the Michigan Alcoholism Screening Test (MAST) for the Detection of Alcohol-Related Problems Among Male Geriatric Outpatients," American Journal of Geriatric Psychiatry, Vol. 9, 2001, pp. 30-34.

[42] J. R. Milam and K. Ketcham, "Under the Influence: A Guide to the Myths and Realities of Alcoholism," New York: Bantam Books, 1983.

[43] D. R. McCreary, M. D. Newcomb and S. W. Sadava, "The Male Role, Alcohol Use, and Alcohol Problems: A Structural Modeling Examination in Adult Women and Men,” Journal of Counseling Psychology, Vol. 46, No. 1, 1999, pp. 109-124.
[44] R. Gilbertson, R. Prather and S. J. Nixon, "The Role of Selected Factors in the Development and Consequences of Alcohol Dependence," Alcohol Research and Health, Vol. 31, No. 4, 2008, pp. 389-399.

[45] R. W. Hingson, T. Heeren and M. R. Winter, "Age at Drinking Onset and Alcohol Dependence: Age at Onset, Duration, and Severity," Archives of Pediatrics and Adolescent Medicine, Vol. 160, 2006, pp. 739-746.

[46] M. Hari, “Personal Communication,” August 2009.

[47] L. N. Blume, N. H. Nielson and J. A. Riggs "Alcoholism and Alcohol Abuse among Women: Report of the Council on Scientific Affairs,” Journal of women's health, Vol. 7, 2008, pp. 861-870. August 2009. http://en.wikipedia.org/wiki Alcoholism 